\title{
ESTUDIOS DE GEOARQUEOLOGÍA EN EL ESTRECHO DE GIBRALTAR: ELABORACIÓN DEL CATÁLOGO DE LA LITOTECA GEOARQUEOLÓGICA DEL DEPARTAMENTO DE CIENCIAS DE LA TIERRA DE LA UNIVERSIDAD DE CÁDIZ
}

\author{
GEOARCHAEOLOGY STUDIES IN THE STRAIT OF GIBRALTAR: \\ CATALOGING OF THE GEOARCHAEOLOGICAL LITHOTHEQUE \\ IN THE DEPARTMENT OF EARTH SCIENCES OF THE UNIVERSITY OF CÁDIZ
}

José Luis RAMÍREZ-AMADOR

UGEA-PHAM, Universidad de Cádiz, Puerto Real, Cádiz

Correo electrónico: joseluisramirezamador@gmail.com

\begin{abstract}
Resumen: Se presenta con este trabajo la primera edición elaborada del catálogo de la litoteca de la Universidad de Cádiz. En él se trabaja desde una propuesta geoarqueológica y arqueométrica para la caracterización de materias primas minerales, especialmente de naturaleza silícea, usadas por diferentes sociedades en la Prehistoria, en la región histórica denominada "estrecho de Gibraltar". Constituyéndose así una potente herramienta para el estudio de las estrategias de aprovisionamiento, captación y distribución de recursos por parte de las sociedades citadas. Se crea con ello una plataforma de investigación, con espacios destinados al almacenaje de muestras (cuya colección supera las 5.000 muestras) y la recopilación de información accesibles a la comunidad científica.
\end{abstract}

Palabras Clave: Litoteca, geoarqueología, arqueometría, sílex y rocas silíceas, Prehistoria, materias primas minerales.

\begin{abstract}
The first edition of the catalogue of the lithotheque of the University of Cádiz is presented with this paper. The work is based on a geoarchaeological and archaeometric proposal for the characterization of mineral raw materials, mostly siliceous, used by different societies in Prehistory, in the historical region of the "Strait of Gibraltar". It is thus a powerful tool for the study of provision strategies, acquisition, and distribution of resources by these societies. A research platform has been created with spaces for the storage of samples (whose collection exceeds 5,000 samples), information gathering and accessibility to the scientific community.
\end{abstract}

Keywords: Lithotheque, geoarchaeology, archaeometry, flint and siliceous rocks, Prehistory, raw materials.

Sumario: 1. Introducción. 2. Contexto geológico. 3. Contextualización Arqueológica en el estrecho. 4. La interdisciplinaridad metodológica en arqueometría y geoarqueología: Litoteca. 5. Catálogo LitUCA. 6. Resultados. 7. Conclusiones. 8. Agradecimientos. 9. Bibliografía.

\section{Introducción}

El presente trabajo se enfoca en la resolución de cuestiones relativas al aprovisionamiento y distribución de materias primas líticas a lo largo de la historia de la humanidad, especialmente durante la prehistoria, en el área de la región denominada estrecho de Gibraltar, una zona de gran interés histórico por su posición de puente entre el Suroeste de Europa y el norte de África. Esta área, considerada como "región histórica" es definida como tal, por primera vez por Tarradell (1959). Ha sido ocupada durante el Pleistoceno y Holoceno por diversas sociedades, que han explotado los recursos de caza, pesca y recolección (Ramos, 2012). Cuenta con una secuencia histórica y arqueológica que ofrece muchas semejanzas en la técnica y modos de vida que, generalmente, han sido explicados a partir de modelos basados en ideas difusionistas (Ramos, 2014). Los trabajos realizados en los últimos años en ambas orillas plantean nuevas hipótesis que rompen con la idea difusionista de la co- 
lonización a través de Oriente Medio, defendiendo el área del estrecho de Gibraltar como un puente y no como una frontera (Tarradell, 1959; Ramos, 2012), donde existieron relaciones y contactos de grupos humanos portadores de estas tecnologías (Weniger, 1991). Muchas de las influencias apreciadas en la tecnología paleolítica de la península Ibérica son claramente africanas (Pericot, 1942) pero continuamente, desde la arqueología tradicional, se dan atribuciones al origen y llegada de los grupos humanos desde Oriente Medio (Mellars y Stringer, 1989). Estas nuevas hipótesis de contactos y movilidades organizadas de los grupos humanos, desde el Pleistoceno, pueden explicarse a partir de las variaciones glacioeustáticas (Ramos et al., 2009), convirtiendo la región del estrecho de Gibraltar en una zona de gran interés para explicar el acceso a Europa de diferentes comunidades que tuvieron su origen en África durante el Pleistoceno inferior, medio y superior (Ramos, 2012). Por lo tanto, es fundamental profundizar en los estudios de diferentes campos y ciencias auxiliares que nos permitan avanzar en futuras investigaciones arqueológicas en la región, entre las que se encuentran las disciplinas presentadas en este trabajo: la arqueometría y geoarqueología.

La aproximación geoarqueológica al estudio del registro material, para el estudio del comportamiento humano, implica el uso de métodos y técnicas de las geociencias en la resolución de los problemas arqueológicos (Dominguez-Bella et al., 2006; Arteaga y Schulz, 2008). El aprovisionamiento de materias primas ha sido un tema de gran interés en los estudios arqueológicos. Conocer la fuente de captación de dichos materiales puede permitirnos trazar los recorridos de las rocas encontradas en los diferentes yacimientos desde su origen, ayudándonos a conocer las distintas estrategias de obtención y consumo como factor fundamental en la comprensión de la organización existente en los grupos sociales de homínidos (Binford, 1980).

Podemos emplear la cualidad que poseen las rocas de vincular pequeños eventos aparentemente intrascendentes e inconexos dentro de un yacimiento con la totalidad del paisaje. Para ello, estudiar los paisajes en los que se encuentran los yacimientos, desde el punto de vista de la disponibilidad y características de las materias primas líticas, se plantea como una solución para esta cuestión. Centrándose en analizar los contextos regionales como una importante fuente de datos que permita comprender las conductas identificadas en los yacimientos (Roy-Sunyer, 2016).

Para dar respuestas a estas cuestiones ya citadas, en el estudio de materias primas, se plantea la elaboración de una litoteca geoarqueológica. Debido a la magnitud y complejidad que ello conlleva, se ha propuesto la elaboración de este trabajo como un proyecto, constituido de varias fases, cuyo objetivo es la participación y colaboración de diferentes grupos de investigación dentro de esta universidad y fuera de ella. Dicho proyecto se ha denominado LitUCA, en referencia a "Litoteca de la Universidad de Cádiz".

\section{Contexto geológico}

El área estudiada engloba a nivel geográfico dos regiones de distintos continentes que a priori parecen muy dispares pero que son muy similares a nivel geológico. Esta similitud dota a la región del estrecho de una gran peculiaridad, y es el hecho de que las rocas situadas a ambos lados de él son prácticamente iguales desde un punto de vista geológico. Este dato es fundamental como punto de partida en los estudios geoarqueológicos y arqueométricos para el área del estrecho (Domínguez-Bella et al., 2006, 2016).

La Cordillera Bética (sur de la península Ibérica), junto con el Rif (norte de África), representan los elementos más occidentales del conjunto de cadenas alpinas circunmediterráneas. Quedando limitadas al norte por el Macizo Ibérico y su cobertera, y al sur por la Cuenca de Alborán. Las Cordilleras Béticas constituyen un orógeno formado durante la evolución Eo-, Meso- y Neo-Alpina en el área del Mediterráneo occidental (Sanz de Galdeano, 1990). Tradicionalmente se ha dividido en: Zonas Externas, divididas en Prebético y Subbético; Zonas Internas, donde encontramos los Complejos Nevadofilábride, Alpujárride y Maláguide; y el Complejo del Campo de Gibraltar, compuesto por dos conjuntos: Mauritánico y Numídico (Vera y Martín-Algarra, 2004).

$\mathrm{Al}$ otro lado del estrecho algunos de estos materiales presentan continuidad litoestratigráfica. Las Cordilleras Béticas y Rifeña rodean el extremo oeste del Mediterráneo formando una estructura orogénica arqueada denominada Arco de Gibraltar (Martín-Serrano, 1985) (Figura 1). Este empezó a formarse por la convergencia de Eurasia y África hace $25 \mathrm{Ma}$, durante la era Cenozoica. La apertura del estrecho supuso la inmersión local de 


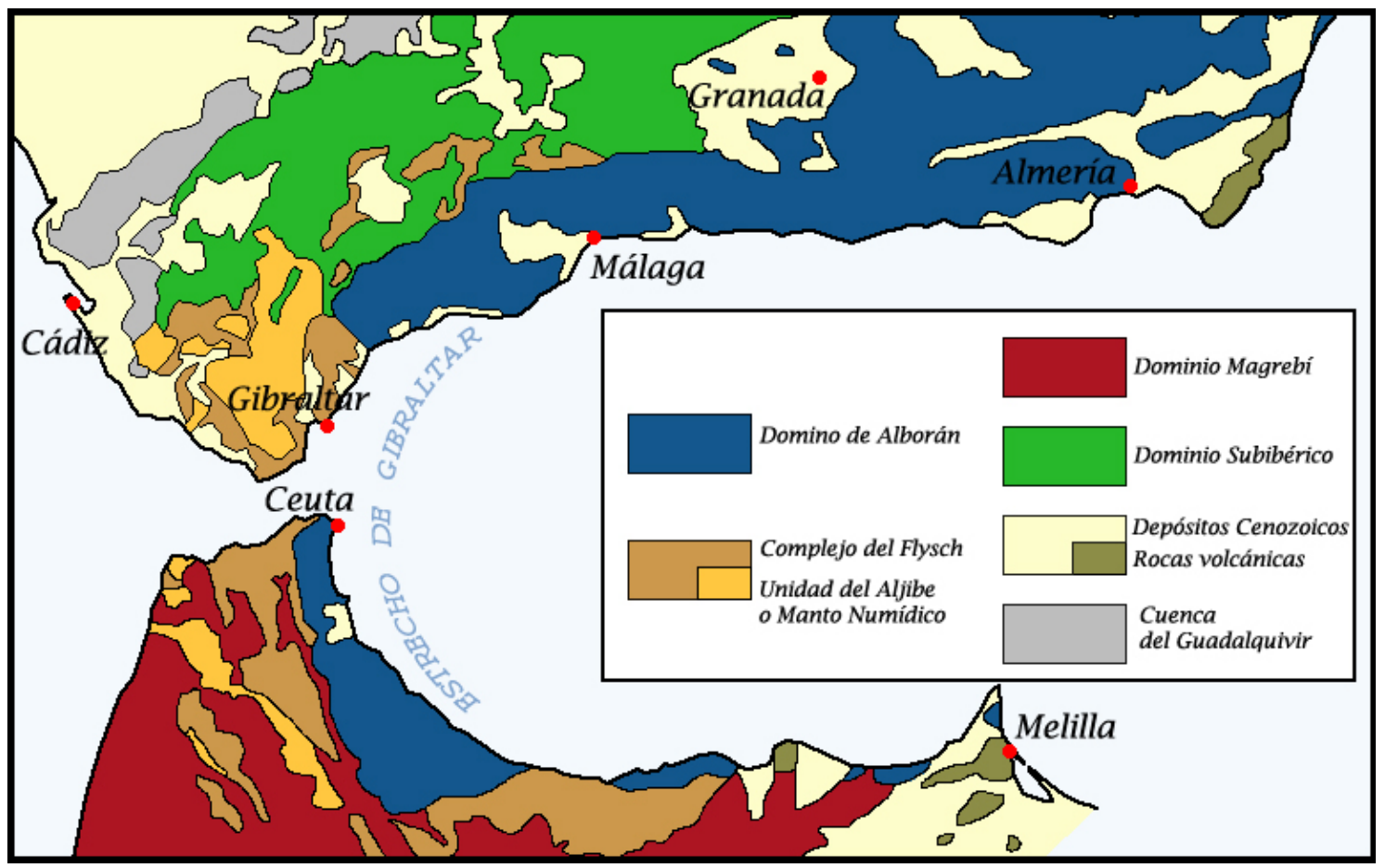

Figura 1. Dominios geotectónicos del Arco de Gibraltar.

(Elaborado a partir del mapa en Gutiérrez-Mas et al., 2016).

los terrenos pertenecientes al prisma de acreción del Arco de Gibraltar. Es por ello que, en la Cordillera Rifeña, es decir la parte del arco emplazada en el norte de África, podemos reconocer las Zonas Internas y las Zonas Externas (Kornprobst y Durand-Delga, 1985), que se encuentran separadas por unas zonas intermedias de Flysch, conocidas informalmente como los Mantos del Flysch. Es este hecho el causante de que muchos de los materiales litológicos, a un lado y otro del estrecho, presenten las mismas características petrológicas. Esto hace realmente difícil realizar geocaracterizaciones precisas, especialmente del sílex, relacionado principalmente con depósitos jurásicos y en menor medida cretácicos.

\subsection{Entorno geológico del Suroeste peninsular}

El estudio del material lítico, en esta primera fase de la litoteca, se ha centrado en los materiales correspondientes a la zona sur occidental andaluza. La provincia de Cádiz y parte de la provincia de Málaga, debido a su posición geográfica, es una región de particular interés, ya que a través del ya mencionado Arco de Gibraltar permiten la conexión morfológica y geológica con las Cadenas Alpinas del norte de África. La provincia de Cádiz se caracteriza por ofrecer un paisaje muy heterogéneo, en cierta manera condicionado por la variedad litológica y estructural que presenta. Dentro del marco fisiográfico gaditano podemos distinguir conjuntos geográficos mayores, como son las Cordilleras Béticas, la Depresión del Guadalquivir y el Golfo de Cádiz, conjuntos que a su vez se encuentran geológicamente ligados entre sí (Gutiérrez-Mas et al., 1991). Los materiales pueden agruparse en función de la edad y posición tectónica de las rocas aflorantes en el entorno de la región, diferenciando entre materiales preorogénicos y postorogénicos.

Entre los materiales preorogénicos, únicamente una parte de la Cordillera Bética aflora en la provincia gaditana; están representados por el Subbético medio, el Penibético y las Unidades del Campo de Gibraltar. En general, estos materiales presentan una estructura tectónica en "mantos de corrimiento"; se trata de materiales anteriores a las principales deformaciones orogénicas de la zona, que fueron elevados, plegados, fracturados y trasladados por cabalgamientos desde su posición original, por efecto de la Orogenia Alpina, (Martín-Algarra, 1987). Su edad oscila entre el Triásico (como materiales retrabajados) y el Mioceno medio, y corresponden a los materiales más occidentales de la Cordillera Bética. Los materiales históricamente clasificados como triásicos 
(Gutiérrez-Mas et al., 1991), correspondientes a las facies germano-andaluzas, son incluidos actualmente en los complejos caóticos subbéticos (Vera, 2004), y constituyen la base estratigráfica de las unidades subbéticas (Gutiérrez-Mas et al., 1991). Sobre estas facies se encuentran reposando los materiales jurásicos, de composición principalmente caliza. Sobre esta podemos encontrar margas, margocalizas y calizas con nódulos de sílex (Domínguez-Bella et al., 2016). En las sierras de la Silla, sierra del Pinar, Lagarín, Malaver y otros relieves de la sierra de Cádiz, el Jurásico Inferior presenta calizas con sílex, margocalizas y margas. Por el contrario, el Jurásico Medio y el Jurásico Superior están formados, principalmente, por margas y margocalizas radiolaríticas con brechas y conglomerados calcáreos. Los tipos de rocas citados anteriormente son la principal fuente de los distintos tipos de sílex y radiolaritas explotadas en la Prehistoria del sur peninsular, y más concretamente, en el área de las provincias de Cádiz y Málaga, ya sea en afloramientos in situ, como ocurre en Malaver-Montecorto (Málaga) (Vallespí y Cabrero, 1980-1981) o en materiales producto de la erosión y transporte de los mismos, como podrían ser las mélanges dentro de Unidades del Campo de Gibraltar del valle del rio Turón, los conglomerados de edad Oligoceno, que afloran en el Campo de Gibraltar, o las terrazas fluviales de los ríos Guadalete, Majaceite y Palmones (Domínguez-Bella et al., 2016). Los materiales de edad cretácica aparecen, principalmente, en la zona norte de la provincia. Estos se caracterizan por estar formados principalmente de margas y margocalizas. Durante el Cretácico medio aparecen niveles oscuros e intercalaciones de sílex (Gutiérrez-Mas et al., 1991). Para Domínguez-Bella et al. (2016) estos sílex cretácicos han podido ser también utilizados, junto con los del Jurásico, pero a menor escala. En la zona sur de la provincia, cercana al estrecho, afloran los flyschs cretácicos (Martín-Algarra, 1987). Los flyschs cenozoicos son muy abundantes en la provincia, encontrándose dos grandes mantos de corrimiento: la unidad Algeciras y la unidad del Aljibe. Esta última está presente en el norte de África, conocida como Manto Numídico (Martín-Algarra, 1987). La Unidad de Algeciras, compuesta en su mayoría por materiales margosos y arcillosos y calizas detríticas, comprenden edades entre Cretácico superior y Mioceno, apareciendo en la provincia de Cádiz una gran cantidad de afloramientos (Gu-
tiérrez-Mas et al., 1991). La Unidad del Aljibe o Manto Numídico destaca por la presencia de areniscas silíceas muy puras (Martín-Algarra, 1987; Gutiérrez-Mas et al., 1991). Esta unidad se extiende hacia el este por la Serranía de Ronda y por el sur hasta el Rift, describiendo el Arco de Gibraltar (Domínguez-Bella et al., 2016). Este tipo litológico, usado casi siempre sobre el soporte de cantos rodados, ha sido muy empleado por las sociedades cazadoras-recolectoras y tribales neolíticas, en las industrias líticas de numerosos yacimientos en la provincia de Cádiz y norte de Marruecos (Domínguez-Bella, 2002), como por ejemplo en el Campo de Gibraltar (Rio Palmones, Ringo-Rango, etc.) o en el abrigo de Benzú (Ceuta) (Domínguez-Bella et al., 2006). En algunos puntos de los afloramientos podemos encontrar también sílex bandeados y porosos, asociados a estos materiales, como ocurre en Tarifa (Domínguez-Bella et al., 2016). Por último, encontramos las unidades Almarchal, Algarrobo y el Flysch de Ubrique, estos niveles están compuestos por arcillas y margas verdes, con niveles intercalados de margo-calizas y microbrechas calcáreas pertenecientes al Senoniense superior. Estos presentan equivalencia al norte de África, concretamente en la Unidad de Tánger (Domínguez-Bella et al., 2006).

Sobre los materiales preorogénicos, y una vez ocurridas las principales fases de plegamiento, reposan en discordancia materiales de carácter autóctono. Estos materiales forman parte de la Depresión del Guadalquivir y de las Depresiones intramontañosas de la parte occidental de la Cordillera, igualmente en la Depresión de Ronda (Vera y Martin-Algarra, 2004). Los principales afloramientos de este tipo de depósitos están ubicados al norte y noroeste de la provincia de Cádiz, sobre todo en la zona de Jerez de la Frontera, en la cuenca del rio Guadalete y en el litoral, además de en la Depresión de Ronda, en la provincia de Málaga. Tienen edades entre el Mioceno superior y el Holoceno. Por su litología, condiciones de sedimentación y edad, se pueden dividir en tres grupos: Mioceno superior, Plioceno y Cuaternario (Gutiérrez-Mas et al., 1991).

\section{2. Áreas fuente potenciales para las materias primas silíceas en el occidente de Andalucía}

Considerando las diferentes litologías descritas, respecto a la geología regional y sus edades geológicas, y partiendo de los estudios realizados 
por Domínguez-Bella (2002), se pueden describir diferentes fuentes de materias primas que pudieran haber sido empleadas potencialmente por las sociedades prehistóricas. Podemos citar los siguientes grupos y edades de los materiales geológicos:

- Materiales históricamente clasificados como Triásico-Keuper: Estos materiales se datan actualmente como sedimentos del Mioceno medio dentro de los complejos caóticos subbéticos, los cuales comprenden una masa incoherente y con pérdida de continuidad en la que hay gran cantidad de materiales más antiguos (triásicos en su mayor parte) de naturaleza arcillosa y salinos con olistostromas de carbonatos, yesos, sales y rocas subvolcánicas (Vera, 2004). Estos materiales no suelen ir asociados a materiales de composición silícea. Existen excepciones puntuales como los pequeños afloramientos hallados en 2002 cerca de El Berrueco (Medina Sidonia), con un sílex masivo y poroso, está en relación con areniscas y carniolas triásicas y pudo ser aprovechado como materia prima por estas sociedades, además, se ha observado la presencia de posibles áreas de producción en la zona (Domínguez-Bella et al., 2016). Puntualmente aparecen cristales de cuarzo bipiramidales que pudieron ser empleados como objetos de adorno, prestigio o ritual (Vijande, 2006; Vijande et al., 2019).

- Materiales del Jurásico y Cretácico: Los afloramientos pertenecientes al Subbético y Penibético, constituyen áreas fuente potenciales para la captación de sílex y radiolaritas, materias primas muy empleadas por las sociedades prehistóricas en ambas orillas del estrecho de Gibraltar (Domínguez-Bella et al., 2016). Existe una evidente ausencia de grandes bloques de sílex en el resto del entorno geológico de la provincia, a excepción del límite de la sierra gaditano-malagueña (Ramos et al., 1992), en sitios claramente subbéticos como Montecorto (Vallespí y Cabrero, 1980-1981). Algunos de estos sílex aparecen en posición secundaria, como los de las Unidades del Campo de Gibraltar (Domínguez-Bella et al., 2016). La existencia de una gran variedad de sílex, vinculado al consumo en la zona por parte de las sociedades prehistóricas recientes para la producción de grandes láminas, hace suponer un carácter alóctono para las mismas, cuyo origen se localizaría en grandes centros de producción (Ramos et al., 2009). Debido a la inexistencia de grandes nódulos en los sitios cercanos, se piensa que el consumo del sílex regional estaría enfocado a la elaboración de productos laminares de menor tamaño y para actividades cotidianas (Ramos, 2012). Otros elementos de edad jurásica empleados en la prehistoria fueron las radiolaritas (pero siempre en menor proporción al sílex), areniscas y cuarcitas. Otras áreas de material silíceo jurásico son los depósitos de conglomerados del Oligoceno (material retrabajado), que afloran en la zona de Los Barrios, en el Campo de Gibraltar, en afloramientos como el cerro Calderón o la cantera la Coracha, estos cantos de sílex presentan en ocasiones sílex de muy buena calidad (Castañeda y Domínguez-Bella, 2008).

- Materiales del Cenozoico: otros materiales muy empleados en la región son las areniscas del Aljibe, pueden presentarse en algunos niveles con litologías muy compactas o cementadas, que pueden producir cantos rodados de gran consistencia. Esta litología ha sido muy empleada por las sociedades cazadoras-recolectoras del Paleolítico, y se ha podido observar en las industrias líticas de muchos yacimientos de la provincia de Cádiz y norte de Marruecos, como los estudiados en el Campo de Gibraltar o en el abrigo de Benzú (Domínguez-Bella et al., 2006, 2016; Ramos, 2012). Este material parece haber sido explotado por grupos humanos adscritos al Achelense, con tecnología de modo II, como atestiguan los yacimientos del Arroyo de la Cueva-río Iro, explotándose principalmente a partir de cantos rodados de los depósitos de terrazas fluviales de dichos cauces (Domínguez-Bella et al., 2016). Otros materiales del Terciario estudiados son los pertenecientes al yacimiento del Realillo-Loma de Enmedio, donde se ha hallado sílex masivo y muy poroso, que ha sido asociado con niveles del flysch del Campo de Gibraltar, lo que indicaría la posibilidad de la existencia de áreas-fuente de materiales silíceos en afloramientos inmediatos, que pudieron ser de interés para la explotación durante la Prehistoria (Domínguez-Bella et al., 2016). En la campiña gaditana, al norte 
de Jerez, entre El Cuervo y Lebrija, aparecen facies lacustres y palustres de edad pliocena, asociadas a importantes depósitos horizontales de sílex de colores pardos a pardos oscuros. Se presentan junto a un nivel de abundante materia orgánica, asociados a calizas lacustres con numerosos gasterópodos (Ramos et al., 2019). En El Cuervo existe constancia de que estos sílex fueron utilizados por comunidades prehistóricas, aunque con un uso muy local, debido a la mala calidad del material para la talla (Ramos et al., 2019).

- Materiales cuaternarios: los sílex y radiolaritas de captación local en la zona, que presentan gran variedad litológica, están asociados a materias primas del Jurásico y Cretácico. Aparecen en depósitos fluviales o aluviales del Cuaternario, suelen hallarse como pequeños cantos rodados junto con cuarcitas y areniscas compactas, como los recuperados en los ríos Guadalquivir, Guadalete, Majaceite o Palmones (Domínguez-Bella et al., 2016). Existen niveles cuaternarios de arenas rojas en numerosos afloramientos repartidos por el litoral gaditano, como los presentes en La Barrosa y cabo Roche; o arenas amarillas de la Fontanilla, en la costa de Cádiz. Otras áreas fuentes posibles son los depósitos aluviales cuaternarios en el Campo de Gibraltar o terrazas fluviales y marinas como el Embarcadero del río Palmones. Otras materias primas que pudieron ser empleadas como elementos de talla son las silexitas del Santuario de la Virgen de la Luz de Tarifa, pero hasta el momento no se han hallado piezas que lo constaten (Domínguez-Bella et al., 2016).

\section{Contextualización Arqueológica en el estre- cho}

El estudio geoarqueológico de los sitios, así como el control de los productos arqueológicos, han permitido valorar una ordenación histórica y diacrónica de los enclaves localizados a partir de los trabajos de numerosos autores. Se presenta en este apartado una síntesis sobre el actual panorama en la investigación relativa a los estudios sobre materias primas líticas usadas en la Prehistoria del Suroeste de España y sobre las posibilidades de futuros estudios (geología, caracterización lito- lógica, aprovisionamiento, rutas migratorias, etc.) al respecto de dichas materias primas, asociadas a grupos humanos en la orilla norte del estrecho de Gibraltar y en el norte de África.

\subsection{Sistemas de captación, distribución y con- sumo de las materias primas por los grupos de cazadores-recolectores-pescadores}

Desde un punto de vista antropológico los grupos humanos de cazadores-recolectores presentan características que permiten considerarlos con criterios históricos como sociedades. Dicha comprensión resulta básica para entender las prácticas económicas en relación a la obtención de los alimentos a través de la caza, la pesca y la recolección (Ramos, 2012). La peculiar conformación social de estos grupos viene definida por el acceso a la propiedad, que en este caso se ejerce sobre la fuerza de trabajo y los instrumentos de producción. Estas bases son las que van a definir el modo de producción y el control social sobre la naturaleza, por el desarrollo de unas técnicas, de un trabajo y de unas relaciones sociales específicas (Bate, 1986). El conocimiento de su equipamiento técnico y de sus patrones de asentamiento y movilidad, dentro de estos grupos nómadas, está demostrando que los grupos humanos cazadores-recolectores-pescadores no eran simples saqueadores de la naturaleza, sino que se comportaban desarrollando evidentes estrategias para cazar y ocupar territorios de forma estacional y cíclica (Weniger, 1991).

El modo de producción de estos grupos humanos puede verse concretado en el modo de vida (Vargas, 1990). Éste viene representado por los modos de organizar la vida y producir en un mismo marco de relaciones sociales de producción. El modo de vida se produce en una determinada región, en este caso la región histórica del estrecho de Gibraltar, con un ecosistema y recursos definidos, tanto animales como vegetales. Para un mismo modo de producción, por ejemplo: cazador-recolector, se han podido estudiar diferentes modos de vida: cazadores, cazadores-recolectores o pescadores-mariscadores. Con una clara relevancia del medio, pero han sido los propios grupos los que han presentado la capacidad de organizar las diferentes estrategias socioeconómicas con líneas muy claras de producción y trabajo (Ramos, 1998; 2012). Al considerar algunas características básicas de estas sociedades cazadoras-recolecto- 
ras hay que indicar que, en general, los ciclos de producción y consumo son breves (Bate, 1986). Estos grupos empiezan a desarrollar procesos económicos simples, de gran interés en el registro arqueológico, con algunas formas de distribución y cambio. Estas se concretan en función de las características del entorno y basadas principalmente en materias primas para la elaboración de herramientas o productos tecnológicos ya elaborados y objetos relacionados con la decoración, abalorios, etc. (Ramos, 2012).

La forma de territorialización (Bate, 1986), que pueden ser vinculadas a verdaderas posesiones consensuadas o a apropiaciones estacionales (Ramos, 2012), se relacionan claramente con la propia estructura económica y con la forma de apropiación de los territorios, siendo la tecnología muy importante, pues es determinante a la hora de definir las estrategias socieconómicas de obtención de recursos. Estas sociedades son complejas y ricas en matices, en relación al control de la técnica y la productividad natural (Bate, 1986). Con todo ello, se relaciona el buen conocimiento del medio, de las propiedades de minerales y rocas, así como los efectos de consumo (Ramos, 2012), que varían en cada región en clara relación a la biocenosis y a factores abióticos. La obtención y aprovechamiento para la vida cotidiana de estos recursos marcan los diversos casos de movilidades de estos grupos.

Los primeros estudios importantes de ordenación de la secuencia para la captación de materias primas en las terrazas del río Guadalquivir fueron propuestos por Vallespí (1986). En ellos se estudian las sociedades autoras de la tecnología relacionadas con el Modo II-Achelense, y de un modo general, se aprecia la captación de materias primas locales, inmediatas a los yacimientos. En especial, la arenisca compacta local parece tener un uso generalizado por estas sociedades (Domínguez-Bella et al., 2016). En estudios de la comarca del Alto Vélez, aparecen sílex de mala calidad, provenientes de las terrazas de los ríos Vélez, Guaro, Sabar; o areniscas silíceas de procedencia local (Ramos, 1988; Vallespí et al.., 1989-1990). En el rio Guadalhorce-Guadalteba parece existir también un aprovechamiento local con sílex proveniente de las sierras de edad Jurásica próximas (Becerra 2015, 2019; Cabello, 2016). En la banda atlántica encontramos un claro aprovechamiento local de materias primas, donde existe una dominancia de litologías formadas por areniscas com- pactas del Aljibe (Domínguez-Bella, 2008; Ramos, 2008), materiales de edad mesozoica y cenozoica, de procedencia local y explotados principalmente a partir de cantos rodados en depósitos de terrazas fluviales de edad cuaternaria. Muy similar es el caso del Campo de Gibraltar, con estudios de talla realizados en areniscas del Aljibe (Castañeda y Domínguez-Bella, 2008). La cuenca del río Guadalete muestra también el aprovechamiento del material de las terrazas fluviales inmediatas (Domínguez-Bella et al., 2016).

Los estudios realizados por Vallespí en 1986, indican una tecnología musteriense presente en el sur peninsular y muy bien definida, con núcleos centrípetos, tecnología levallois y presencia clásica de raederas y puntas. Las sociedades relacionadas con la tecnología de modo III-Musteriense, parecen captar materias primas locales. Hay casos estudiados como los del Guadalquivir (Vallespí, 1986), y otros autores, donde se muestra el aprovechamiento del sílex de las terrazas y afloramientos de ríos como el Vélez, Guaro, Sabar, así como de abundantes materias primas situadas en Cerro Alcolea y su entorno inmediato; Guadalete; banda atlántica de Cádiz (Domínguez-Bella, 2008; Ramos, 2008) donde se han encontrado sílex masivos, porosos y esferulíticos; o Gibraltar (Domínguez-Bella et al., 2016). Además, en diferentes puntos del litoral gaditano, principalmente entre El Puerto de Santa María y Conil, podemos encontrar depósitos de arenas rojas de edad cuaternaria, en ellos, se pueden hallar productos tallados elaborados sobre cantos rodados. Estos son principalmente de cuarcitas, cuarzos metamórficos lechosos, filitas, areniscas calcáreas, calizas, gneis o sílex muy alterados (Domínguez-Bella et al., 2016). Existen evidencias de la presencia de sílex de buena calidad, de procedencia subbética, en el litoral de Cádiz en enclaves como La Barrosa, que podrían indicar movilidad de bandas cazadoras-recolectoras superiores a los $80 \mathrm{~km}$ (Domínguez-Bella, 2008; Ramos, 2008).

Los grupos vinculados con el Modo IV-Paleolítico Superior, parecen indicar mayores ejemplos de territorialización, en el marco de las movilidades estacionales, de inicio de procesos de verdaderas posesiones consensuadas o apropiaciones estacionales relacionados con la propia estructura económica y con la forma de apropiación de los territorios. Estos grupos presentan una mayor complejidad, en relación al control de la técnica, un buen conocimiento del medio y de las propiedades 
de los minerales y rocas (Ramos, 2012). La obtención y aprovechamiento para la vida cotidiana de estos recursos aporta información para obtener un mejor conocimiento respecto a las movilidades de estos grupos (Domínguez-Bella et al., 2016). En la banda atlántica de Cádiz se han documentado hasta el presente testimonios de sitios estratificados con tecnología característica de Modo IV-Paleolítico Superior en: Loma del Puerco, III-8; Casa de Postas, III-9; Puntalejo I, III 10; Puntalejo II, III-12; La Fontanilla I, III-13; playa del Puerco, III-15; Cala del Aceite, VI-4 y Caños de Meca. Registros de carácter Epipaleolítico se documentan en: VII-25 en Cala Picacho (Ramos, 2008). Hay que considerar el inmediato contexto de los Abrigos de Cubeta de la Paja y Cuevas de Levante en Benalup y evidentemente los interesantes depósitos documentados en Gibraltar y en otros sitios del Campo de Gibraltar, como Torre Almirante. Es destacable la proximidad de los sitios localizados de la tecnología de modo IV, en contextos geomorfológicos cerca del litoral, con conexión estratigráfica con depósitos de glacis y con coluviones con cantos subangulosos de matriz arcillo-arenosa. Respecto a las materias primas, se ha observado un claro predominio del sílex, encontrándose los registros más completos en la III-12. La Fontanilla I y III-13. playa del Puerco (Domínguez-Bella, 2008; Ramos, 2008; Domínguez-Bella et al., 2016). Este sílex parece presentar un aprovechamiento principalmente local, asociado generalmente a la extracción de cantos de edad jurásica en depósitos aluviales o fluviales de edad cuaternaria; arenas rojas de La Barrosa o Cabo de Roche; depósitos aluviales de arenas amarillas, como el caso de la Fontanilla; o los depósitos de terrazas fluviales cuaternarios como los presentes en el río Palmones y el embarcadero del río Palmones (Domínguez-Bella, 2008; Ramos, 2008; Domínguez-Bella et al., 2016). Otras litologías estudiadas, como pueden ser las radiolaritas de edad jurásica, aparecen siempre en menor proporción que los sílex, areniscas o cuarcitas. Asociadas, en algunos casos, a depósitos secundarios en terrazas fluviales o marinas, como ocurre en los yacimientos del río Palmones o afloramientos primarios puntuales del subbético de la sierra de Cádiz (Domínguez-Bella et al., 2016). Se documenta así en el Paleolítico un destacado aprovechamiento local en los grupos de cazadores-recolectores para el sur peninsular. La existencia de sílex proveniente de la Serranía de Ronda indica procesos de movilidad significativos.

\subsection{Sistemas de captación, distribución y con- sumo de las materias primas por sociedades tribales neolíticas y clasistas iniciales}

El cambio de las sociedades cazadoras-recolectoras a la tribalización conllevó una transformación en los elementos del proceso productivo: un cambio de la propiedad sobre el objeto de trabajo, ejerciéndose, a partir de ese momento, la propiedad del mismo. Pero con este cambio no se abandonan los recursos cinegéticos y los vegetales silvestres, sino que incluso otros como la pesca y el marisqueo llegan a alcanzar una explotación intensiva en algunas zonas (Ramos, 2012). Estas comunidades no sufren grandes procesos de transformación en su forma comunal, respecto a las sociedades de cazadores-recolectores, sino en su contenido, que se ejercerá, a partir de este momento, sobre el objeto de trabajo (Bate, 1986 Vargas, 1990), no sólo sobre el suelo agrícola, sino sobre los recursos cinegéticos, territorios de pesca, marisqueo o recolección.

Se produce una variación en el patrón de ocupación territorial caracterizado por la existencia de asentamientos estables (campamentos base o pequeñas aldeas) desde los que parten expediciones a otros terrenos de forma estacional para la obtención de productos de caza, pesca, marisqueo y recolección de materias primas abióticas. La posibilidad de estos asentamientos permanentes permite la acumulación de aquellos recursos almacenables, estableciendo las condiciones de sedentarización (Ramos, 2012; Vijande et al., 2019). La propia sociedad se vuelve doméstica, hallándose en la distribución comunitaria de la propiedad de la tierra la base de la domesticación, variando la conformación de bandas por agregación a comunidades cuyas nuevas relaciones sociales se basan en la filiación entre parientes. Las relaciones de parentesco organizan la distribución de la propiedad, el trabajo y el consumo (Ramos, 2012). Los estudios sobre las sociedades tribales y clasistas iniciales de la Prehistoria Reciente parecen indicar una relación directa entre los procesos de producción lítica y la estructura social y económica de estas sociedades (Domínguez-Bella et al., 2016).

En este marco de organización social, del mundo tribal neolítico existen ya auténticas redes de distribución de productos (Ramos, 2008). En el ámbito de las sociedades tribales neolíticas se documentan procesos de circulación de productos líticos desde las zonas de producción (Ramos et 
al., 2009). Se han estudiado diferentes centros de producción, como los entornos de la Axarquía de Málaga, Ardales-Turón (Lozano et al., 2010; Becerra, 2015, 2019), la Serranía de Ronda (Aguayo et al., 1990) o la sierra de Cádiz, que son explotados y desde donde se produce por estas sociedades una distribución de los productos líticos elaborados a entornos geográficos inmediatos (Domínguez-Bella et al., 2016), con evidencias de grandes láminas de sílex distribuidas en algunos poblados y enterramientos de Andalucía Occidental (Ramos et al., 2009) y cuya procedencia de la materia prima es claramente subbética.

Igualmente, los productos líticos en la banda atlántica de Cádiz (Ramos, 2008) y en las campiñas y marismas de Jerez (Ramos et al., 2019) presentan un carácter alóctono para aquellos sílex de buena calidad, que han sido relacionados con afloramientos del Subbético en las sierras de Cádiz, Málaga y Granada. Se evidencian unas zonas de producción registradas en las sierras del Subbético de Cádiz-Ronda (Vallespí y Cabrero, 19801981), de Málaga, principalmente en la zona de Ardales-El Burgo (Lozano et al., 2010) o Granada y en la zona de Loja y una clara ausencia de estas materias primas en las zonas de Andalucía occidental (Ramos, 2012).

En las sociedades clasistas iniciales el estudio de los estados prístinos se vincula con un paso decisivo en la historia de la Humanidad, reflejándose el abandono dentro de las contradicciones planteadas en las sociedades cazadoras-recolectoras y tribales comunitarias, de ciertas formas ideológicas de igualdad comunitaria primitiva, hacia sociedades clasistas donde se realiza un ejercicio de poder despótico por parte de grupos privilegiados sobre una mayoría explotada (Bate, 1984). El modo de producción continúa teniendo una base agropecuaria. Hay una nueva relación entre las clases respecto a la propiedad de los medios de producción, lo que conlleva contradicciones en las relaciones sociales (Bate, 1986). El acceso a la propiedad regula así el marco de las relaciones clasistas y el propio sistema de relaciones de producción.

Es a partir de esta formación social clasista cuando se produce una intensificación en los procesos de distribución de productos, vinculados a la organización del trabajo. La propiedad conlleva un uso objetivo, como capacidad de pertenencia de bienes y permite entender las relaciones sociales. Además, existe un marco ideológico que da forma justificativa e institucional a dicha estructura económica (Ramos, 2012). Con la creación de estas sociedades se consolida la estructura política primigenia de estado y se documentan procesos de redistribución desde centros nucleares (Arteaga, 2002). Con esta implementación sociopolítica se integran los procesos de distribución de materias primas, entre las que se encuentra el sílex, que ahora son redistribuidas hacia áreas periféricas desde centro nucleares del territorio (Arteaga, 2002).

\section{La interdisciplinaridad metodológica en ar- queometría y geoarqueología: Litoteca}

En las últimas décadas, la aplicación de técnicas científicas a la caracterización de materiales ha llegado a convertirse en un elemento fundamental en la investigación arqueológica. Las metodologías y técnicas empleadas habitualmente en ramas de la Geología, como pueden ser la mineralogía y petrología para el estudio y caracterización de minerales y rocas, pueden ser empleadas como herramientas muy útiles en su aplicación al estudio de materiales arqueológicos, constituyendo una fuente de información de posibilidades en auge. Esta contribución, junto con otras disciplinas o especialidades del área (como pueden ser los estudios geomorfológicos), ha permitido un enorme incremento de la «calidad» de los trabajos y datos manejados y por tanto mayores posibilidades interpretativas en aspectos tales como la movilidad humana, intercambio, tecnología, etc. (Domínguez-Bella y Morata-Céspedes, 1995). Desde la Universidad de Cádiz se vienen empleando durante las tres últimas décadas numerosas técnicas o métodos arqueométricos y geoarqueológicos, enfocados en el estudio de materiales arqueológicos. Las técnicas utilizadas para el estudio en detalle del material que compone esta litoteca están enfocadas en el estudio mineral y composicional. Algunas de las utilizadas para el estudio de las piezas contenidas en la colección de la litoteca han sido: difracción de rayos-X, espectroscopia de infrarrojos, microscopía electrónica de barrido con análisis cualitativo mediante energía dispersiva de rayos-X y microscopía óptica. Las técnicas mencionadas siempre son complementarias a un estudio estereoscópico previo de los materiales geológicos estudiados.

- Microscopía Óptica: Estudio a partir de láminas delgadas. Esta técnica permite abordar 
la descripción física en términos visuales, mediante la microcopia de luz polarizada. Este tipo de estudio aporta una valiosa información mineralógica, petrológica y paleontológica, además, de aspectos relacionados con la génesis y evolución de la roca. Las láminas elaboradas en el proyecto LitUCA se han añadido a la colección de referencia.

- Difracción de Rayos-X (DRX): empleada para la identificación de fases minerales. Las muestras son trituradas en mortero en forma de polvo y posteriormente tamizadas a un tamaño de partícula inferior a 40 micras (método de polvo cristalino)

- Espectroscopia de Infrarrojos (IR): se determinan fases minerales puras a partir de la trituración y tamización al tamaño de $20 \mu$, a partir de una pequeña cantidad de muestra, que es mezclada con $\mathrm{KBr}$, prensada y transformada para obtener una pastilla. Los resultados son complementarios a los obtenidos previamente por los DRX.

- Microscopía electrónica de barrido (MEB): empleada en la identificación química cualitativa de los elementos presentes en las partículas de la muestra y especialmente para la observación y estudio de las superficies de los minerales presentes (Domínguez-Bella y Morata-Céspedes, 1995).

El objetivo final de estas técnicas aplicadas a la arqueología, y en concreto para la elaboración de la litoteca, es poder determinar las posibles áreas fuente de las materias primas minerales y conocer el carácter autóctono o alóctono de las mismas. Estos estudios nos permiten obtener una importante información sobre la movilidad de las sociedades cazadoras-recolectoras. En relación con las sociedades tribales y/o clasistas iniciales de la Prehistoria Reciente, esto permite analizar el proceso económico de producción, distribución y consumo de dichos productos líticos, así como los fenómenos de distribuciones de largo recorrido para productos líticos de prestigio (Ramos et al., 2009; Domínguez-Bella et al. 2016).

\section{Catálogo LitUCA}

\subsection{Elaboración de la litoteca}

En primer lugar, para la elaboración de este trabajo de catalogación se debía conocer la proce- dencia y cantidad de materiales que en él se han estudiado. El estudio de parte de la colección petroarqueológica perteneciente al Departamento de Ciencias de la Tierra de la Universidad de Cádiz. La casi práctica totalidad de dichas piezas fueron recogidas por el catedrático Salvador Domínguez-Bella quien, desde 1981 hasta la actualidad, ha realizado una actividad de recolección, prospección y almacenaje de una inmensa cantidad de muestras.

Con el objetivo de realizar un estudio más sistematizado, se ha realizado previamente un inventario de todas las piezas recogidas en la colección. Esta primera etapa del trabajo-proyecto ha permitido identificar, clasificar y almacenar una cantidad superior a las 5.000 piezas, pudiendo ser georreferenciadas e inventariadas cada una de ellas (Figura 2). Todo ello ha sido necesario para poder realizar, una vez finalizado dicho inventario, el catálogo de la litoteca.

La litoteca se constituye, por tanto, como una colección de referencia para las materias primas que, potencialmente, pudieron haber sido explotadas como recursos para la manufactura de instrumental lítico desde la prehistoria. Esta colección se crea con el objetivo de convertirse en una herramienta indispensable para el estudio de estrategias de aprovisionamiento y captación de recursos minerales por parte de las mencionadas sociedades. Se crea con ello una potente plataforma de investigación, con espacios destinados al almacenaje de muestras, recopilación de información y base de datos accesible a la comunidad científica. La colección está centrada en cualquier materia prima que haya podido ser empleada como material de talla. Destacando, por su mayor captación y explotación, las rocas silíceas (sílex, radiolaritas, jaspe, ópalo, etc.), areniscas y cuarcitas.

\subsection{Elaboración de una ficha-tipo para cada muestra: Metodología de clasificación}

El primer problema que se debe abordar a la hora de elaborar el catálogo es aquel referente a la elección de los criterios generales de organización de la colección, de manera que permitan articular $y$, posteriormente, posibiliten el acceso a toda la información que se va a recabar de cada de una de las piezas junto con su documentación gráfica. Quiere esto decir que de cada una de ellas se debe registrar la información relativa a su materia prima, geología del material, georreferencia, ca- 


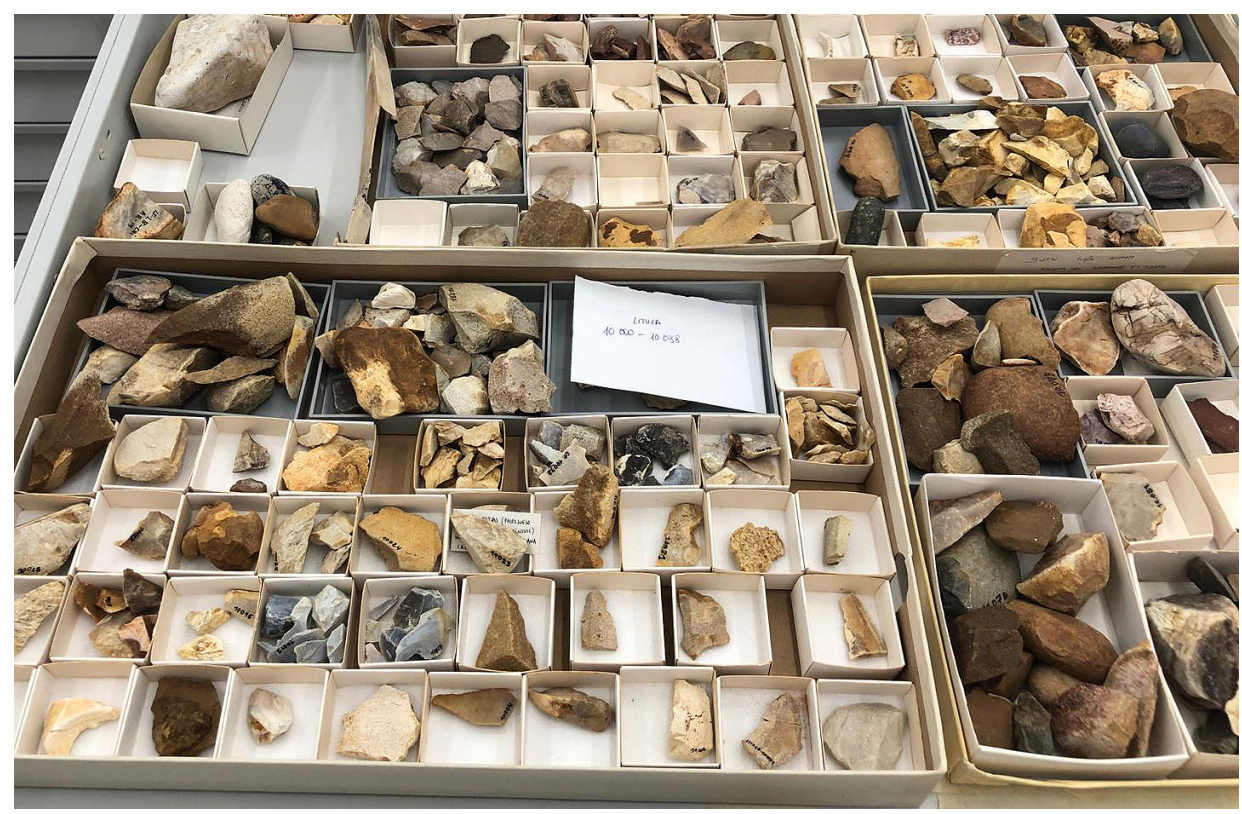

Figura 2. Imagen de algunas muestras catalogadas y georreferenciadas pertenecientes a la colección LitUCA. (Fotografía de J.L. Ramírez-Amador, 2019).

racterísticas de dicha materia prima, yacimiento, distribución etc., que permitan realizar un registro efectivo, permitiendo cotejarlas con diferentes materias primas halladas en los yacimientos. El condicionante de partida para registrar cada uno de los elementos es que los materiales deben tener una ubicación física conocida y constatada. Por otro lado, este es el principal objetivo didáctico que se persigue con este proyecto. Para ello se precisa establecer una serie de criterios generales a fin de determinar cómo se integran las piezas en las secciones y subsecciones establecidas. Se propone la agregación tanto de materias primas (no artefactuales) como de artefactos líticos. Ello obliga a consignar en la ficha individual información relativa a su tecnología y, eventualmente, a su tipología.

Con esta finalidad se han diseñado, unas fichas que serán el eje principal del proyecto LitUCA y que están basadas en el modelo presentado por Biró y Dovosi. (1991) para el Museo Nacional Húngaro (Figura 3). Estas fichas han sido empleadas como plantilla para la mayoría de las litotecas que podemos encontrar en la actualidad. La ficha propuesta por el museo húngaro se diseñó hace tres décadas, por lo que se ha visto necesaria la actualización de los parámetros a registrar actualmente a la vista de las necesidades y objetivos que se plantean en este proyecto.

La base de datos LitUCA está estructurada en un catálogo de fichas, cada una de las cuales corresponde a una muestra concreta de la litoteca.

\section{Resultados}

Para este trabajo, en una primera versión del catálogo de la litoteca, se ha obtenido como resultados una gran cantidad de fichas correspondientes al estudio de un total de 1.905 piezas, que se han podido catalogar y clasificar en detalle, agrupándose en un total de 331 fichas de estudio (Figuras $4 a, 4 b, 4 c)$. Esta primera versión del catálogo, que debido al gran volumen de fichas no es posible incluir en este trabajo, abarca yacimientos de toda la costa gaditana (además de Gibraltar) y las localidades interiores colindantes a ella.

Las piezas restantes, correspondientes al resto de la península Ibérica y parte de Europa y norte de África, se están clasificando igualmente, pero no se incluyen en esta primera versión del catálogo. Las litologías estudiadas, principalmente materias primas sin trabajar, corresponden a: Sílex (1556 p.), cuarcitas (143 p.), areniscas compactas (94 p.), ortocuarcitas (30 p.), radiolaritas (32 p.), conglomerados (21 p.), ópalos ( 3 p.), jaspes ( 5 p.), silexitas ( 3 p.), calcedonias ( 4 p.), cuarzos ( 3 p.), filitas ( 4 p.), arcosas ( 2 p.), doleritas/diabasas ( 2 p.), calizas (2 p.) y un nódulo de sílex.

Una vez acabada la primera fase del proyecto, que consistirá en realizar fichas para el cómputo 
Lithotheca inv. nr.: L 86/001

Other inv. nr: - Pieces: 8

Collected by: Gyarmati P.-Biró K., Exchange material available: $\mathrm{F}$

Petroarchaeological name: rhyolite Synonymes: -

Genetical group: igneous;

Geological age: Miocene

Character of the locality: PG,

Distribution: - Local exploitation: -

Source: H - Tokaj mts. -

Abaújszántó-Krakkó mt.

Coordinates (Lat./long): N 48.17 / E 21.12

Description: black, glassy, non-transparent,

Munsell colour: N2-N3

Transparency: 0

Texture: fluidal

Pattern: -

Fracture: uneven, flaky

Lustre: -

Quality: 1

Analyses: -, analysis reference nr: -

References: Gyarmati 1977,

Perlaky 1972 flaky fracture

\begin{tabular}{|c|c|}
\hline \multicolumn{2}{|c|}{\begin{tabular}{l|l} 
№ inventario LitUCA: & \\
Características Geoarqueológicas y arqueométricas \\
\end{tabular}} \\
\hline \multicolumn{2}{|c|}{ Características Geoarqueológicas y arqueométricas } \\
\hline Cantidad de muestras: & \\
\hline Recogido por: & \\
\hline Colección de procedencia: & \\
\hline Disp. para el intercambio: & \\
\hline Nombre petroarqueológico: & \\
\hline Sinónimos: & \\
\hline Grupo genético: & \\
\hline Edad Geológica: & \\
\hline Características de la localidad: & \\
\hline Distribución: & \\
\hline Fuente: & \\
\hline Coordenadas (lat./long.) & \\
\hline Descripción: & $\begin{array}{l}\text {-Color Munsell: } \\
\text {-Transparencia: } \\
\text {-Textura: } \\
\text {-Estructura: } \\
\text {-Fractura: } \\
\text {-Lustre: } \\
\text {-Calidad: }\end{array}$ \\
\hline Analítica: & \\
\hline Características Ar & deológicas \\
\hline Yacimiento: & \\
\hline Año de la excavación: & \\
\hline Periodo/Edad & \\
\hline Industria lítica/ Uso & \\
\hline $\begin{array}{l}\text { Distribución geográfica de la } \\
\text { litología: }\end{array}$ & \\
\hline $\begin{array}{l}\text { Descripción/observaciones de la } \\
\text { pieza: }\end{array}$ & \\
\hline Referencias bibliográficas: & \\
\hline
\end{tabular}

Figura 3. A la izquierda: modelo utilizado por Biro et al., (1991), en la Litoteca del

Museo Nacional de Hungría.

A la derecha: modelo empleado en la colección LitUCA. total de piezas que componen LitUCA, el objetivo es ofrecer la información sistematizada de forma digital. Para ello, todos los estudios comentados tienen como finalidad la creación de una base de datos digitalizada en la que se tendrán en cuenta diversos parámetros de estudio, dependiendo del tipo de elemento lítico estudiado (materias primas o artefactos).

\section{Conclusiones}

Las conclusiones extraídas de esta primera versión de la litoteca de la Universidad de Cádiz son:

- Se presenta un modelo de base de datos, que servirá como herramienta de partida en la sistematización de la información mineralógica, petrológica, geológica, geográfica y arqueológica disponible en la zona geográfica de la orilla norte del estrecho de Gibraltar.
- Se clasifican y sistematiza su información para 1.905 ejemplares. Quedando pendiente clasificar el resto de la colección, constituida por más de 5.000 piezas.

- Esta base de datos incluye además otros elementos de apoyo a la docencia y a la investigación, como es el caso de fotografías (distintos aumentos) de los ejemplares, de dibujos de los mismos, analíticas, información bibliográfica e información tecno-tipológica de los especímenes.

- Se establecen relaciones entre los entornos geológicos presentes en la región y las materias primas minerales que han aparecido en su registro arqueológico, de cara a establecer el carácter autóctono o alóctono de las mismas a lo largo de los diferentes periodos históricos. 
Estudios de geoarqueología en el estrecho de Gibraltar: elaboración del catálogo de la litoteca geoarqueológica del Departamento de Ciencias de la Tierra de la Universidad de Cádiz

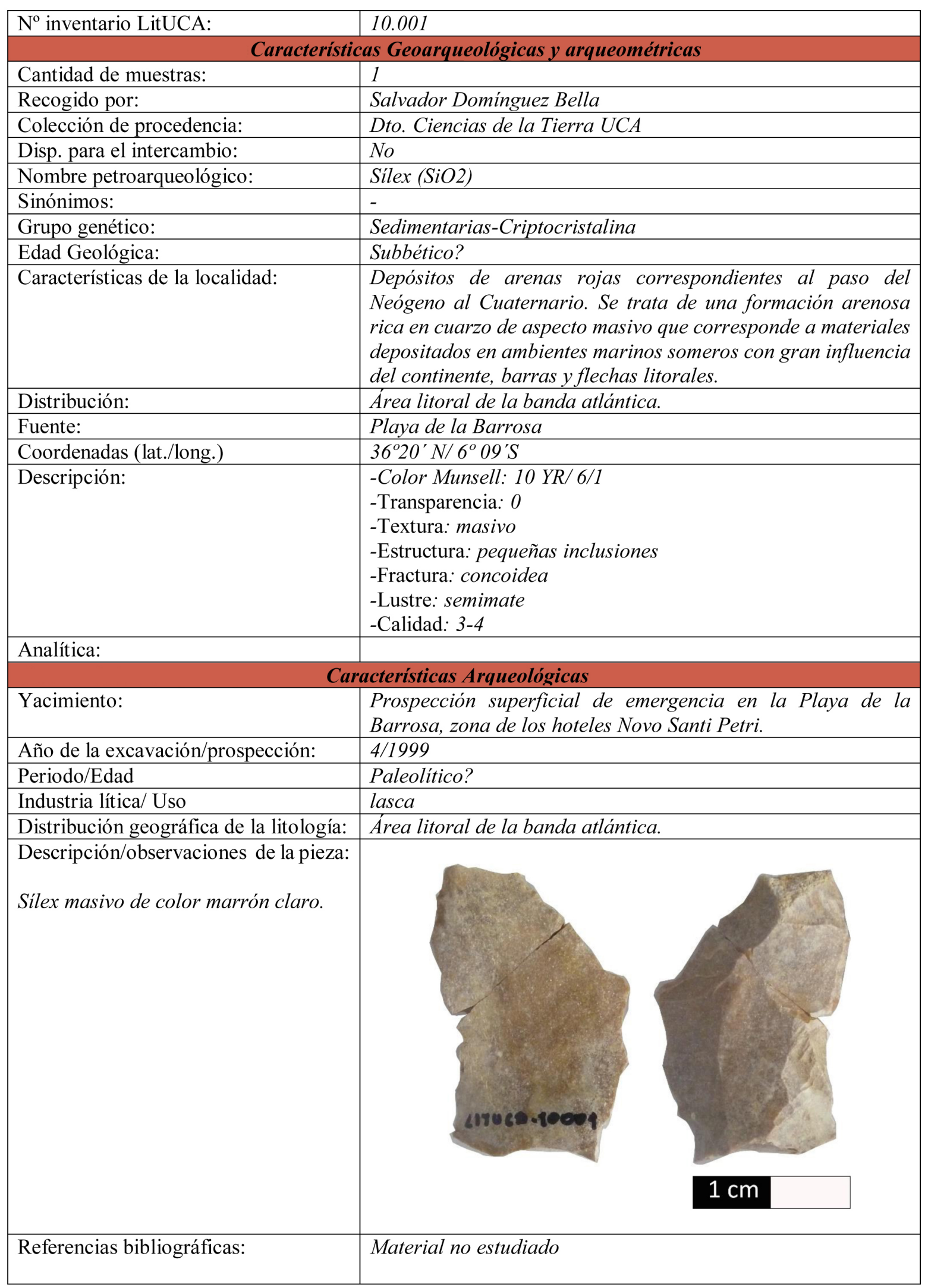

Figura 4a. Diferentes ejemplos del modelo de ficha propuesta para el proyecto LitUCA. Pieza no 10.001, sílex tallado.

Revista Atlántica-Mediterránea de Prehistoria y Arqueología Social 21, pp. 11-28

Universidad de Cádiz 


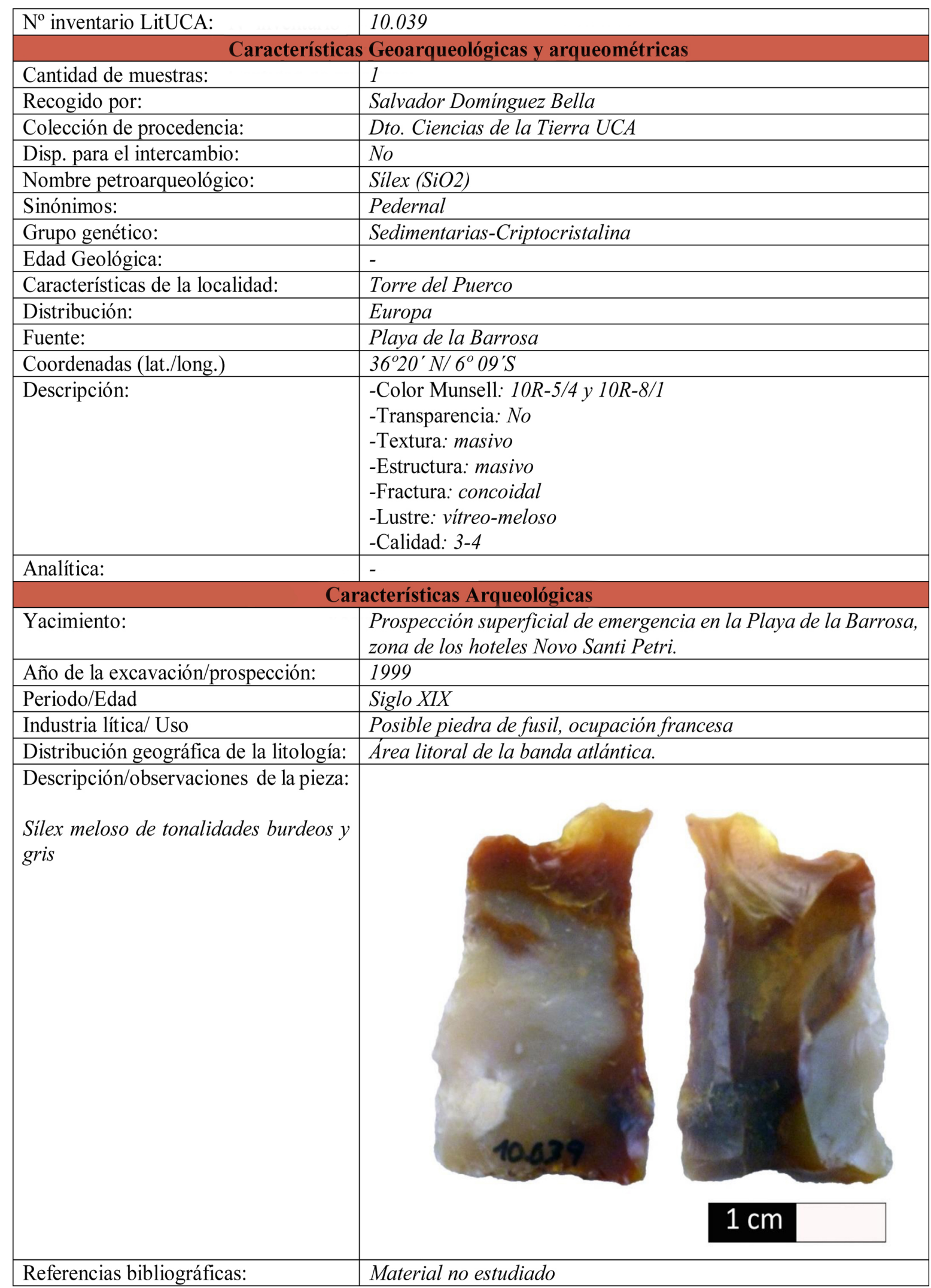

Figura 4b. Diferentes ejemplos del modelo de ficha propuesta para el proyecto LitUCA. Pieza número 10.039, sílex empleado, posiblemente, como piedra de fusil. 
Estudios de geoarqueología en el estrecho de Gibraltar: elaboración del catálogo de la litoteca geoarqueológica del Departamento de Ciencias de la Tierra de la Universidad de Cádiz

\begin{tabular}{|c|c|}
\hline $\mathrm{N}^{\circ}$ inventario LitUCA: & 10.364 \\
\hline \multicolumn{2}{|c|}{ Características Geoarqueológicas y arqueométricas } \\
\hline Cantidad de muestras: & 66 \\
\hline Recogido por: & Salvador Domínguez Bella \\
\hline Colección de procedencia: & Dto. Ciencias de la Tierra UCA \\
\hline Disp. para el intercambio: & No \\
\hline Nombre petroarqueológico: & Sílex (SiO2) \\
\hline Sinónimos: & - \\
\hline Grupo genético: & Sedimentarias-criptocristalina \\
\hline Edad Geológica: & - \\
\hline Características de la localidad: & Nivel de arenas rojas \\
\hline Distribución: & - \\
\hline Fuente: & La Loja Bolonia \\
\hline Coordenadas (lat./long.) & $N^{\circ} 36^{\circ} 0,5^{\prime} 754^{\prime \prime}-W^{\circ} 05^{\circ} 48^{\prime} 383^{\prime \prime}$ \\
\hline Descripción: & $\begin{array}{l}\text {-Color Munsell: Variado } \\
\text {-Transparencia: } 0 \\
\text {-Textura: masiva } \\
\text {-Estructura: Bandeadas y masivas } \\
\text {-Fractura: concoidea } \\
\text {-Lustre: semimate } \\
\text {-Calidad: } 3-3,5\end{array}$ \\
\hline Analítica: & Lámina delgada- LT-BOLO-99 \\
\hline \multicolumn{2}{|r|}{ Características Arqueológicas } \\
\hline Localidad & Baelo Claudia, Bolonia (Tarifa,Cádiz) \\
\hline Yacimiento: & La Loja \\
\hline Año de la excavación/prospección: & 1999 \\
\hline Periodo/Edad & - \\
\hline Industria lítica/ Uso & - \\
\hline Distribución geográfica de la litología: & - \\
\hline $\begin{array}{l}\text { Descripción/observaciones de la pieza } \\
\text { Gran cantidad de inclusiones }\end{array}$ & \\
\hline
\end{tabular}

Figura 4c. Diferentes ejemplos del modelo de ficha propuesta para el proyecto LitUCA. Pieza no 10.364, sílex bandeado, posible materia prima. 


\section{Agradecimientos}

Agradezco especialmente a Salvador Domínguez-Bella (Universidad de Cádiz), tutor del trabajo fin de máster que dio origen a este artículo y director del proyecto LitUCA, y a José Ramos Muñoz, cotutor del TFM, por el seguimiento y revisión de todo el proyecto. A los profesores del departamento de Ciencias de la Tierra de la Universidad de Cádiz Ángel Sánchez Bellón y Javier Martínez-López, por su ayuda en la revisión de los aspectos geológicos, y a los profesores del área de Prehistoria de la Universidad de Cádiz: Eduardo Vijande y Juan Jesús Cantillo Duarte.

\section{Bibliografía}

AGUAYO DE HOYOS, Pedro; MARTÍNEZ FERNÁNDEZ, Gabriel; MORENO JIMÉNEZ, Francisco. 1990: "Articulación de los sistemas de hábitat neolítico y eneolítico en función de la explotación de recursos naturales en la Depresión de Ronda". Cuadernos de Prehistoria de la Universidad de Granada, 14-15, pp. 67-84.

ARTEAGA MATUTE, Oswaldo. 2002: "Las teorías explicativas de los 'cambios culturales' durante la Prehistoria en Andalucía: nuevas alternativas de investigación". En Cajasur (ed.): Actas del III Congreso de Historia de Andalucía. Prehistoria, pp. 247-311. Córdoba.

ARTEAGA MATUTE, Oswaldo; SCHULZ, Horst D., (eds.) 2008: "Geoarqueología y Proceso Histórico en la Bahía de Cádiz". Revista Atlántica-Mediterránea de Prehistoria y Arqueología Social, 10, pp. 55-56.

BATE PETERSEN, Luis Felipe. 1984: "Hipótesis sobre la sociedad clasista inicial". Boletín de Antropología Americana, 9, pp. 47-86.

BATE PETERSEN, Luis Felipe. 1986: "El modo de producción cazador recolector o la economía del salvajismo". Boletín de Antropología Americana, 13, pp. 5-31.

BECERRA MARTÍN, Serafín. 2015: “De las sociedades tribales a las clasistas iniciales en el territorio de los valles Guadalteba y Turón (Vo al IIo Milenio A.N.E.)". Revista Atlántica-Mediterránea de Prehistoria y Arqueología Social, 17, pp. 135-147.

BECERRA MARTÍN, Serafín. 2019: El aprovisionamiento de sílex durante la Prehistoria reciente en la comarca del Guadalteba (Málaga). BAR International Series 2920.

BINFORD, Lewis Roberts. 1980: "Willow smoke and dogs' tails: hunter-gatherer settlement systems and archaeological site formation". American Antiquity, 45, pp. 4-20.

BIRÓ, Katalin; DOBOSI, Viola. 1991: Litotheca Comparative Raw Material Collection the Hungarian National Museum. Hungarian National Museum. Budapest.

CABELLO LIGERO, Lidia. 2016: La ocupación humana del territorio de la comarca del río Guadalteba (Málaga). Tesis Doctoral. Universidad Nacional de Educación a Distancia. Madrid.

CASTAÑEDA FERNÁNDEZ, Vicente y DOMÍNGUEZ-BELLA, Salvador. 2008: "Materias primas, áreas de captación y tecnología de las sociedades del Paleolítico. El Río Palmones (Los Barrios, Cádiz)". En S. ROVIRA LLORENS; M. GARCÍA-HERAS; M. GENER e I. MONTERO RUIZ (eds.): Actas del VII Congreso Ibérico Arqueometría, pp. 360-367. Museo Arqueológico Nacional-CSIC. Madrid.

DOMÍNGUEZ-BELLA, Salvador (2002): “Geología del Arco de Gibraltar. El Sur de la Península Ibérica y el Norte de África, como fuentes potenciales de materias primas minerales en la Prehistoria". En M. TILMATINE; J. RAMOS y V. CASTAÑEDA (eds.): Libro de Actas de las la Jornadas de Estudios Históricos y Lingüísticos. Universidad de Cádiz. Cádiz.

DOMÍNGUEZ-BELLA, Salvador. 2008: "Las materias primas minerales en los asentamientos de cazadores-recolectores en la banda atlántica de Cádiz durante el pleistoceno superior. Geoarqueología, análisis mineralógico y petrológico". En J. RAMOS (coord.): La ocupación prehistórica de la Campiña Litoral y Banda Atlántica de Cádiz, pp. 127-145. Arqueología Monografías, Junta de Andalucía. Sevilla.

DOMÍNGUEZ-BELLA, Salvador; MORATA-CÉSPEDES, Diego. 1995: “Aplicación de las técnicas mineralógicas y petrológicas a la Arqueometría. Estudio de materiales del Dolmen de Alberite" (Villamartín, Cádiz). Zephyrus, XLVIII, pp. 129-142.

DOMÍNGUEZ-BELLA, Salvador; CHAMORRO MORENO, Simón; RAMOS MUÑOZ, José; BERNAL CASASOLA, Darío. 2006: "Materias primas minerales y geología en el entorno del Abrigo y la Cueva de Benzú (Ceuta)". En G. MARTíNEZ; A. MORGADO y J.A., AFONSO (coords.): Sociedades Prehistóricas, Recursos Abióticos y Territorio, pp. 119-133. Fundación Ibn al-Jatib. Granada. 

geoarqueológica del Departamento de Ciencias de la Tierra de la Universidad de Cádiz

DOMÍNGUEZ-BELLA, Salvador; RAMOS MUÑOZ, José; VIJANDE VILA, Eduardo. 2016: "Materias primas silíceas en la prehistoria del occidente de Andalucía". Siliceous Raw Materials in the Prehistory of Western Andalusia". Cuadernos de Prehistoria y Arqueología de la Universidad de Granada, 26, pp. 327-356.

GUTIÉRREZ-MÁS, José María, MARTÍN ALGARRA, Agustín, DOMÍNGUEZ-BELLA, Salvador; MORAL CARDONA, José Pedro. 1991: Introducción a la Geología de la provincia de Cádiz. Servicio de Publicaciones. Universidad de Cádiz. Cádiz.

GUTIÉREZ-MÁS, José Manuel, GRACIA PRIETO, Javier, LUJÁN MARTÍNEZ, María ; SÁNCHEZ BELLÓN, Ángel. 2016: Geología del Campo de Gibraltar. Geolodía 2016. Cádiz. http://www. sociedadgeologica.es/archivos pdf/geolod\%C3\%ADa16/guias geolodia16/gdia16gui_cadiz.pdf . Consultado el 24 de junio de 2018.

KORNPROBST, Jacques; DURAND-DELGA, Michel. 1985: "Carte géologique du Rif au 1: 50.000. Feuille de Tétouan. Not. Mém”. Serv. Géol. Maroc, 292. Rabat.

LOZANO RODRÍGUEZ, J. Antonio; MORGADO RODRÍGUEZ, Antonio; PUGA RODRÍGUEZ, Encarnación; MARTÍN-ALGARRA, Agustín. 2010: "Explotaciones del sílex tipo "Turón" (Málaga, España): localización y caracterización petrológica y geoquímica". Geogaceta, 48, pp. 163166.

MARTÍN-ALGARRA, Agustín. 1987: Evolución geológica alpina del contacto entre las Zonas Internas y las Zonas Externas de la Cordillera Bética. Tesis Doctoral. Universidad de Granada. Granada.

MARTÍN-SERRANO, Ángel. 1985: "La estructura de las Unidades del Flysch del Campo de Gibraltar. Consecuencias tectónicas y paleogeográficas". Bol. Geol. Min., 96(2), pp. 3-26.

MELLARS, Paul; STRINGER, Christopher. (eds.) 1989: The human revolution: behavioural and biological perspectives on the on the origins of modern humans. Edinburgh University Press.

PERICOT GARCÍA, Luis. 1942: La Cueva del Parpalló (Gandía). CSIC, Instituto Diego Velásquez. Madrid.

RAMOS MUÑOZ, José. 1998.: “Disputados entre la Antropología y la Historia. Un acercamiento socioeconómico para el estudio de los cazadores-recolectores". Revista Atlántica-Mediterránea de Prehistoria y Arqueología Social, 1, pp. 7-32.
RAMOS MUÑOZ, José (coord.) 2008: La ocupación prehistórica de la campiña litoral y banda atlántica de Cádiz. Aproximación al estudio de las sociedades cazadoras-recolectoras y tribales-comunitarias y clasistas iniciales. Arqueología Monografías. Junta de Andalucía. Sevilla. RAMOS MUÑOZ, José. 2012: El Estrecho de Gibraltar como puente para las sociedades prehistóricas. Editorial La Serranía. Ronda.

RAMOS MUÑOZ, José. 2014: "Las sociedades cazadoras-recolectoras del Pleistoceno en la región geohistórica del litoral gaditano y el Estrecho de Gibraltar". En M.J. PARODI (ed.): Ex illo tempore: actas de las I Jornadas de arqueología del bajo Guadalquivir, pp. 15.57. Fundación Casa Medina Sidonia.

RAMOS MUÑOZ, José, DOMÍNGUEZ-BELLA, Salvador; PÉREZ RODRÍGUEZ, Manuela; VIJANDE VILA, Eduardo. 2009: "Producción, distribución y consumo de los productos líticos laminares vinculados a las sociedades comunitarias y clasistas iniciales del ámbito atlántico de Cádiz. Arqueología Social, Geoarqueología, materias primas silíceas, sociedades tribales, sociedades clasistas iniciales". En J.F. GIBAJA; X. TERRADAS; A. PALOMO y X. CLOP (eds.): Les grans fulles de sílex. Europa al final de la Prehistoria, pp. 25-33. Monografies 13. Museo d'Arqueología de Catalunya. Barcelona.

RAMOS MUÑOZ, José; DOMÍNGUEZ-BELLA, Salvador; RAMÍREZ-AMADOR, José Luis; VIJANDE VILA, Eduardo; FERNÁNDEZ-SÁNCHEZ, Diego. 2019: "Caracterización de los sílex de las Peñas de El Cuervo. Aproximación geoarqueológica a los procesos de producción, distribución y consumo de productos líticos por las sociedades tribales y clasistas iniciales". Ligustinus, 7 pp. 46-58.

ROY-SUNYER, Miquel. 2016: Materias primas líticas y su explotación durante la prehistoria en el Pirineo Oriental (NE de Iberia). Tesis doctoral. Universidad Autónoma de Barcelona. Barcelona.

SANZ DE GALDEANO, Carlos. 1990: "Geologic evolution of the Betic Cordilleras in the Western Mediterranean, Miocene to the present". Tectonophysics, 172, pp. 107-119.

TARRADELL, Miquel. 1959: "El Estrecho de Gibraltar. ¿Puente o frontera? (Sobre las relaciones post-neolíticas entre Marruecos y la Península Ibérica)". Tamuda, 7, pp. 124-138.

TARRADELL, Miquel. 1960: Marruecos Púnico. Cremades. Tamuda. 
VALLESPÍ PÉREZ, Enrique. 1986: "El Paleolítico Inferior y Medio en Andalucía”. En Junta de Andalucía (ed.): Homenaje a Luis Siret (19341984), pp. 59-66. Consejería de Cultura. Sevilla.

VALLESPÍ PÉREZ, Enrique; CABRERO GARCÍA, Rosario. 1980-1981: “Calcolítico y Bronce Pleno en el Moral de Montecorto (Ronda) (Colección Pérez Aguilar)". Mainake, II-III, pp. 48-75.

VALLESPÍ PÉREZ, Enrique; RAMOS MUÑOZ, José; MARTÍN CÓRDOBA, Emilio. 1989-1990: “Bifaz del Alto Vélez, del Achelense Superior o de su tradición inmediata". Mainake, XI-XII, pp. 5-10.

VARGAS ARENAS, Iraida. 1990: Arqueología, ciencia y sociedad. Abre Brecha. Caracas.

VERA, Juan Antonio; MARTÍN-ALGARRA, Agustín. 2004: "Cordillera Bética: Divisiones mayores y nomenclatura". En J.M. VERA (ed.): Geología de España, IGME-Sociedad Geológica de España, pp. 348-350. Madrid.
VIJANDE VILA, E. 2006: Prehistoria Reciente de Chiclana de la Frontera. Aportaciones al conocimiento de las formaciones sociales tribales y clasistas iniciales en el marco de la banda atlántica gaditana (libro electrónico). Universidad de Cádiz. Cádiz.

VIJANDE VILA, Eduardo; RAMOS MUÑOZ, José; FERNANDEZ SANCHEZ, Diego; CANTILLO DUARTE, Juan Jesús; PEREZ RODRIGUEZ, Manuela (coord.) 2019: La Esparragosa (Chiclana de la Frontera, Cádiz). Un campo de silos neolítico del IV milenio A.N.E. Arqueología Monografías. Consejería de Cultura y Patrimonio Histórico. Junta de Andalucía. Sevilla.

WENIGER, Gerd. 1991: "Überlegungen zur Mobilität Jägerischer Gruppen im Jungpaläolithikum". Saeculum, 42(1), pp. 82-103. 